\section{Relative Reactivities of the Olefinic and Cyano Links of Acrylonitrile in the Diels-Alder Reaction}

THe Diels-Alder reaction, in which a stable six-membered ring is formed by 1,4-addition of an unsaturated linkage to a diene, has wide synthetic application. The role of the olefinic group as a dienophile is well known ${ }^{1}$. More recently, the addition of the cyano group to dienes with the formation of pyridinic products has been reported ${ }^{2}$. Acrylonitrile presents an interesting example in which the groups $(\mathrm{C}=\mathrm{C})$ and $(\mathrm{C} \equiv \mathrm{N})$, both dienophilic, are present. The present communication reports the results of a study on the reactions of acrylonitrile with butadiene. The relative reactivity of these two links of acrylonitrile in this reaction can be predicted from thermodynamic and kinetic considerations. The free energy changes at $700^{\circ} \mathrm{K}$. for the formation of cyanocyclohexene and vinylpyridine are -21 and $-14 \mathrm{kcal} . / \mathrm{mol}$. respectively. These results are qualitative, since the data for the cyclic products were estimated by the method of group increments ${ }^{3}$; but they show that the two reactions are both thermodynamically feasible in this temperature-range. The ultimate yields are a concern of reaction kinetics. The relative rates of these two reactions, assuming the cyclization to be the rate-controlling step, were calculated from the expression :

$$
k_{a} / k_{b}=\exp \left(\left(S_{a}^{\neq}-S_{b}^{\neq}\right) / R-\left(E_{a}-E_{b}\right) / R T\right),
$$

using the kinetic data of related high-temperature 1)iels-Alder associations. From a consideration of the activation energies of the reactions of acrolein 4 and cyanogen ${ }^{5}$ respectively with butadiene, a minimum value of $-11.9 \mathrm{kcal}$. was obtained for $\left(E_{a}-E_{b}\right)$. The magnitude of $\left(S_{a}^{\neq}-S_{b}^{\neq}\right)$for the activated complexes was taken as approximately $-1 \cdot 1$ e.u. from the difference in entropy of 3-cyanocyclohexene and 2 -vinyldihydropyridine. Accordingly, at $400^{\circ} \mathrm{C}$. in the homogeneous gas phase, it is predicted from these data that the formation of cyanocyclohexene is 5,800 times more rapid than the formation of vinylpyridine.

The experimental study has shown that in the homogeneous reactions at about $400^{\circ} \mathrm{C}$., only cyanocyclohexene is found as product of the addition of acrylonitrile to butadiene. This is in accord with the analysis above, that is, very little, if any, vinylpyridine would be formed. In view of the favourable free-energy changes, the reactions were investigated in the presence of a catalyst. With chromium oxide-aluminium oxide as the catalyst system, acrylonitrile reacts by the $(\mathrm{C}=\mathrm{C})$ and $(\mathrm{C} \equiv \mathrm{N})$ bonds as predicted from the thermodynamic considerations. Taking yields as a measure of the relative rates of reaction, since both groups are competing for the diene, the reactivity of the $(\mathrm{C}=\mathrm{C})$ group is fifteen times greater than the $(\mathrm{C} \equiv \mathrm{N})$ group in the catalysed reactions. A summary of the experimental results is given in the accompanying table.

\begin{tabular}{|c|c|c|c|c|c|}
\hline \multicolumn{4}{|c|}{ Experimental reaction conditions } & \multicolumn{2}{|c|}{ Yields (mol. per cent) } \\
\hline Catalyst & Time & $\begin{array}{l}\text { Temp. } \\
\left({ }^{\circ} \mathrm{C} .\right)\end{array}$ & $\begin{array}{l}\text { Press. } \\
\text { (atm.) }\end{array}$ & $\begin{array}{c}\text { Cyano- } \\
\text { cyclohexene }\end{array}$ & $\begin{array}{c}\text { Vinyl- } \\
\text { pyridine }\end{array}$ \\
\hline 二 & $\begin{array}{r}14 \mathrm{hr} . \\
6 \mathrm{sec} .\end{array}$ & $\begin{array}{l}160 \\
390\end{array}$ & $\begin{array}{l}1 \\
1\end{array}$ & $\begin{array}{l}80 \\
77\end{array}$ & $\overline{-}$ \\
\hline 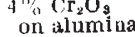 & $4 \mathrm{sec}$. & 430 & 1 & $28 \cdot 0$ & $1 \cdot 8$ \\
\hline
\end{tabular}

A detailed account of this work is to be published elsewhere. Acknowledgment is made to the American Cyanamid Company for a fellowship grant in support of this work.

G. J. J JNZ

Walker Laboratory,

Department of Chemistry, Rensselaer Polytechnic Institute,

Troy, New York. Nov. 24.

${ }^{1}$ Diels, O., and Alder, K., Ann., 480, 9t (1928). Alder, K., and Richert, H. 1:, Ann., 543, 1 , (1939).

${ }_{3}^{2}$ Janz, G. J., and Hawkins, P. J., Nature, 162, 28 (1949)

Andersen, J. W., Beyer, G. H., and Watson, K. M., Nat. Pet. Nexis., 36, R376 (19+4). Bremner, J. G., and Thomas, (i. D., Trans. F'arad. Soc., 43, 779 (1947).

${ }^{4}$ Kistlakowsky, G. B., and Lacher, J. R., J. Amer. ('hem. Shor., 58, 123 (1936).

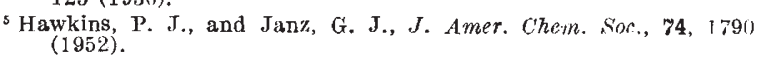

\section{Artefacts produced from 3-lodo-Tyrosine and 3 : 5-Di-iodo-Tyrosine by Heating with}

During a study ${ }^{1}$ of the hydrolysis of native hog thyroglobulin labelled with iodine-131, by a purified protease isolated from hog thyroid glands, fractions eluted from paper chromatograms of the enzyme fission products were treated with $2 N$ sodium hydroxide at $105^{\circ}$ for $16 \mathrm{hr}$. Control aliquots were allowed to stand for the same time at $0^{\circ}$. On application of $n$-butanol extracts of the heated and control samples to paper and development of the chromatograms with $n$-butanol - $n$-pentanol - ammonia ${ }^{2}$ as solvent, unexpected radioactive spots of high $R_{F^{\prime}}$ (at 0.52 and 0.68 ) were observed with the heated samples. since the original eluates were found to contain free mono- and di-iodo-tyrosine and thyroxine, the action of alkali on purified samples of the iodoamino-acids was examined.

Labelled iodo-tyrosines and thyroxine were obtained by the micro-iodination mothod of Lemmon, 'Tarpey and Scott $^{3}$ from L-tyrosine and $3: 5$-di-iodoDL-thyronine respectively. The products were separated from unreacted iodide and other impurities by paper chromatography, $n$-Butanol $-n$-pentanol ammonia was found best for the purification of thyroxine, and n-pentanol - propionic acid -- water $(20: 3: 10)$ for mono- and di-iodo-tyrosine, which were readily separated in this system from each other and from iodide. Incidentally, this acidic solvent system may also be used to separate thyroxine, which has an $R_{F}$ value of 0.80 compared with 0.28 , 0.51 and 0.04 for mono-iodo-tyrosine, di-iodotyrosine and iodide respectively on Whatman No. I paper.

When labelled thyroxine was heated under the above conditions and the product extracted into butanol, a loss of approximately 10 per cent occurred as measured by iodine-131 activity of the extract, but no artefacts were detected. In the case of diiodo-tyrosine, however, there was a four- to eight-fold increase in activity of the butanol-soluble fraction compared with the corresponding extract obtained from a control solution allowed to stand at $0^{\circ}$. Moreover, application of the butanol extract of the heated sample to paper and development with butanol - pentanol - ammonia gave radioactive spots at $R_{F} 0.52$ and 0.72 corresponding to those detected in the hydrolysates from the enzyme fission products. (On the same chromatogram, carrier mono- and 